\title{
Dynamic capability in an under-researched cultural environment
}

\author{
Fatemeh Rezaee $^{\mathrm{a}^{*}}$ and Mostafa Jafari ${ }^{\mathrm{b}}$
}

${ }^{a}$ Master student, Department of Industrial Engineering, Iran University of Science and Technology, Tehran, Iran ${ }^{b}$ Faculty member, Department of Industrial Engineering, Iran University of Science and Technology, Tehran, Iran

C H R O N I C L E

Article history:

Received August 28, 2015

Received in revised format

November 28, 2015

Accepted December 20, 2015

Available online

December 24, 2015

Keywords:

Dynamic capability

Sustainable competitive

advantage

Banking industry

Structural equation modeling

\section{A B S T R A C T}

\begin{abstract}
During the past few years, dynamic capability (DC) has been considered as an important issue in banking industry. This paper presents a survey on dynamic capability and its role on reaching sustainable competitive advantage (SCA) within Mellat bank of Iran (MBI). A valid research instrument is utilized to conduct a survey among 150 managers from MBI. The study utilizes structural equation modelling to examine different hypotheses based on an integrated model of DC and SCA. According to literature studies, expert opinions and exploratory factor analysis, DC is classified into sensing, learning, reconfiguration, and coordination. Furthermore, SCA of the banking industry is classified into three dimensions: market, customer, and financial performance. The results indicate that DC had the greatest effect on the market centered, while it had the least influence on the customer centered.
\end{abstract}

(C) 2016 Growing Science Ltd. All rights reserved.

\section{Introduction}

In the late competitive economy era, the managerial debate on strategic management appears to have reached a crucial stage. The strategic challenge for managers in high velocity markets is to maintain sustainable competitive advantage for which dynamic capability can provide such an advantage (Menon, 2008). Dynamic capabilities (DC) were first put forward by Teece et al. (1997) to explain the creation and capture of sources and methods by firms in environments of rapid technological change. Teece (2007) argued that they are not observable. This is exactly what Winter (2003) claimed in his paper and even wrote as the mystery and confusion of the dynamic capability concept. Actually, the dynamic capabilities analyze competitive advantage and performance in high changing markets (Easterby-Smith et al., 2009). Managers must enhance their understanding of organizational behavior in the business environment to reach sustainable competitive advantage (Makkonen et al., 2014; Rezaee \& Jafari, 2015). It should be noticed that the changing environment transforms the competitive infrastructure of a firm (Teece et al., 1997; Eisenhardt \& Martin, 2000; Zollo \&Winter, 2002; Zahra et 
al., 2006). According to Lin and $\mathrm{Wu}$ (2014), dynamic capabilities can mediate among valuable, rare, inimitable and no substitutable (VRIN) resources of firm to improve performance and reach sustainable competitive advantage. According to Stephen (2010), there are significant positive relationships between dynamic capabilities, i.e. (coordination, learning and strategic competitive response) and the organization performance, i.e. (service delivery, service quality and cost reduction).

The paper introduces a model in relation between DC and the sustainable competitive advantage (SCA) of the banking industry. The banking industry is a major part of Iran's economy. The industry is witnessing considerable growth and fierce competition, which provides a suitable locale for research to examine the influence of DC on SCA of the banking industry. This paper examines what types of components are more crucial to be converted into competitive advantage through dynamic capabilities and also determines a relationship between DC and SCA of the banking industry of Iran. Accordingly, the paper has the following objectives:

(1) to describe and understand components of DC in the banking industry;

(2) to understand what types of components are more crucial to be converted into SCA; and

(3) to examine the relationship between DC and SCA in the banking industry.

Based on the research objectives, the first step of this paper is to build the rationale for a model through reviewing a relevant literature on DC and SCA. The second is to present the methodology and statistical findings as well as discussing its findings in association with literature and research locale, and finally the last step is to present the paper's conclusions.

\section{Literature review}

Nowadays one of the most significant challenges and issues in the technology of information, communication and knowledge is the change rate. Each organization should understand the changes in the available resources so that they could overcome competition and gain competitive advantage in this continuously changing world. It reiterates the view point of some experts such as Porter (1987), Christensen (2001), Reed and Defillippi (1990), who believed that all organizations should obtain sustainable competitive advantage so that they can be secured from catastrophic environmental changes and continue being compatible with environmental requirements. Thus it is undoubtedly required to establish dynamic capability principles as an organizational process to reach such a competitive advantage. In continuation, the core processes of DC (sensing, learning, reconfiguration, coordination) and SCA (market, costumer, financial) and their relation is stated.

\subsection{Dynamic capabilities}

The dynamic capabilities change firm's resources including physical, human, and organizational assets and accordingly firms should constantly adapt, renew, reconfigure and recreate their resources and capabilities in the competitive environment. In other words, the dynamic capabilities are firm's orientation in the adaptation, renewal, reconfiguration and recreation of resources. The core capabilities have to respond to external changes, although the process in which dynamic capabilities are embedded may be specific to the firm and the industry (Wang \& Ahmed, 2007). Helfat et al. (2007) describe dynamic capabilities as the capacity of an organization purposefully to create, extend, and modify its resources that includes the tangible, intangible, and human resources as well as capabilities which the organization owns and controls are achieved to a higher economic value than their competitors. Mathiassen and Vainio (2007) claimed that dynamic capabilities have been coined to capture the firm's ability to adapt to unpredictable and changeable environments. They allow the firm to reconfigure its resources and respond to market changes effectively. Foerstl et al. (2010) described dynamic capabilities in which their specific forms will differ from the company to another company. It should be noticed that they have common features even when they are implemented in different firms. 
Eisenhardt and Jeffey (2000) argued that dynamic capabilities are a set of specific and identifiable process such as product development and strategic decision making. One of the purposes of this paper is to provide a model to explore the explaining effect by sensing, learning, reconfiguration, and coordination over Mellat banks' dynamic capabilities based on the studies carried out by Teece (2007) and Menon (2008).

\subsubsection{Sensing}

Opportunity discovery and creation can originate from the recognition capacities of individuals and organizational processes, such as research and development activity. The sense means the realization ability of opportunities and threats, individual's capabilities and the knowledge and learning capacities of the organization particularly about understanding customer needs, decision making and practical wisdom (Nonaka \& Toyama, 2007). It has to study and survey the customer expectations, current market situation and organizational capabilities and then the results can be analyzed by experts and specialists to develop activities such as the suppling customer needs, shaping new products, and responding marketplace and so on. The rigorous synthesis and updating of the above mentioned items can be embedded in business processes designed by the management or planning unit in the organization. If firms cannot be successful in such activities, they will not be able to assess market and technological developments, and will probably miss opportunities to others (Casson, 1997). Over time information decay, organizations must devise mechanisms and procedures to update information and management. To reach the above mentioned objectives we have to figure out customers, suppliers, collaborators, competitors' potentials, and organizational personnel that are active in such activities. In fact, at this stage the dynamic capabilities involves sensing, understanding and developing techniques and methods for identification of customer needs, competitor activities, and business models that build competitive advantage through utilization of valuable, rare, inimitable and no substitutable resources.

\subsubsection{Learning}

Learning is a concept for characterizing a process for facilitating the creation of new knowledge and means generating new thoughts and reflections to solve organizational problems and enhance its scientific and practical capabilities (Nonaka et al., 2001). Learning can be created in social space in order to knowledge brokering, articulation, codification and pursuing new initiatives and solutions. Learning as a capability is the ability to acquire, assimilate, transform and exploit existing knowledge and generate new knowledge (Zahra \& George, 2002).

\subsubsection{Reconfiguration}

Fast changing markets compel the firms to reconfigure their asset structure to implement the necessary internal and external transformation (Amit \& Schoemaker, 1993). Assets are more valuable in combination than in isolation because the combination gives a firm a more sustainable competitive advantage. Managerial decisions should take the optimal configuration of assets. In the other point view, the process of reconfiguration transforms the existent structure of resources into new ones that match the changing environment. The reconfiguration can include three major mechanisms gain or release of resources, combination of resources and redeployment of resources. Of course there are other approaches to reconfiguration such as reconfiguration through innovation, imitation, experimentation, etc. (Menon, 2008).

\subsubsection{Coordination}

The firm's ability to evaluate the value of existent resources and integrate them to form new competences has been defined coordination capability (Iansiti \& Clark, 1994; Amit \& Schoemaker 1993). Coordination processes can go through communication, scheduling, assignment and other 
related activities. The lack of efficient coordination and integration of different resources may describe why apparently slight technological changes have overwhelming effected on necessary firms' competitive positions in a market (Teece et al., 1997). The effective substantiation of coordination processes by the firm management is of special importance. Coordination capabilities elevate the coordination and integration of firms to most effectively acquire more information about their customers' needs and hence managed performance (Helfat \& Reubitschek, 2000).

\subsubsection{Interrelationship among the core processes}

The ability of opportunities and threats sense is originated to learning. Learning can provide reconfiguration conditions to enhance processes of research and development, to select new technologies, and to complement innovation coordinately in order to develop analytical systems to sense, learn, filter, shape, and calibrate opportunities and threats. Learning capability can shape reconfiguration by effectively acquiring, assimilating, transforming, and exploiting the knowledge. Learning can facilitate reconfiguration, also resources are allocated, tasks are assigned and activities are synchronized through coordination. Capability of coordination can help deploy the reconfigured resources through effective contribution, representation, and interrelation after sensing and learning (Menon \& Mohanty, 2008). The proposed model of dynamic capability have been derive from model was provided by Menon (2008).

\subsection{Competitive Advantage}

Although there are many different viewpoints among the discussed theories to reach SCA, they are similar in one way which aim to maximize the organizational competitive advantage and improve the organization's position among their competitors. It has been a long disputation about how organizations could reach to sustainable competitive advantage. Also many experts have revealed their opinions for such a matter such as Porter who believed that cheap labor and natural resources are not enough for good economy requirements (porter 1985 cited by Andersen, 2013). A competitive advantage is the ability which is obtained through resources and attributes that helps a firm perform at a higher level than the other competitors in the same industry or market. When a firm reaches a competitive advantage, prevented imitation by competitors, resisting erosion by competitor behavior and achieving sustainable competitive advantage are considered as obvious results. However preventing imitation is not permanent; the firm should make any effort to delay this occurrence to gain the maximum benefit from its competitive advantage (Reed \& Defillippi, 1990; Pearce \& Robinson, 2000; Christensen, 2001). According to Barney (2000) "a firm has a competitive advantage when it applies a value creating strategy while any current or potential competitors are deprived to implement the strategy simultaneously and they are also not capable of replicating that". A competitive advantage of firm is assumed as a sustainable paradigm as long as competitors are unable to duplicate it; in this sense it would not last if they were aware of how they could imitate it. Note that industry type has a significant effect on a period of calendar time that a firm enjoys a concept of sustained competitive advantage so that sustainability lasts longer in high-tech industry than other Industries.

Prahalad and Hamel (1990) reported that Western and Japanese companies could conquest competitors to standardize product cost and quality. Although these competencies could be considered as an option to a firm but nowadays they are not dramatically emphasized as only sources to gain a competitive advantage. In other words cost and quality can be as an enabler of a firm to overcome competitors but they are not enough. Surveys were conducted by Prahalad and Hamel (1990) to identify why a service quality of Pakistan telecom cannot result to a firm competitive advantage. The study demonstrated that the telecom industry has a low rating on personal attention to customers and understanding their needs. The question of what leads to a sustainable competitive advantage is not only about today's economic crisis, but also is a question that each company should follow to find a fairly feasible answer (Oliver, 2000). According to Reed and Defillippi (1990) the sources of competitive advantage are as numerous 
as firm activities. A research including a study of 59 articles in 8 fields (strategic management, strategic management of marketing, marketing management, information technology, knowledge management, resources-based theory, entrepreneurship, and human resource management) demonstrated that among Porter's triple strategies, the strategy of differentiation has captured highest attention (Hamidizadeh \& Taheri, 2013). A successful company should focus on its core competence and invests in development of activities creating value and reaches core competence that is the source of comtetive advantage. Core competence is considered as a fundamental concept for competitive strategy in a highly competitive market which is identified as knowledge set helping a company to perform in a different way from competitors and results to a competitive advantage. The core competence concept has been implemented to an organization identifying and efficiently utilizing its strength. Gupta et al. (2009) further argued that core competence is a collection comprised of communication, involvement and a deep commitment across organizational boundaries. Ljungquist (2008) demonstrated that core competence has been emerged to justify business diversity at large companies and provide support for some internal processes including product development. In 1990, Prahalad and Hamel introduced companies' ability as a real source of competitive advantage empowering business to overcome competitors through rapidly changing environment by consolidating technologies and production skills. It has to be emphasized that a firm could reach sustainable competitive advantage if it enjoys having rare, unique and none-replaceable resources. Gupta et al. (2009) point out these resources are not generally capable of creating a competitive advantage which is in higher level than others. A company needs to answer the questions of how it can use available sources and how to create new resources and finds a new approach to develop a new type of product and services and finally how these resources which are considered as a special form of final products and services can create a competitive advantage to a firm and contribute to create the firm's value. Surveys conducted by Holliday (2001) showed that sources of firm's competitive advantage should be supported by human factors. According to his argument, factors including organizational classes, knowledge management, leadership styles, and work teams and so on have more considerable impacts on effective use of the sources. Management is the most effective component of a companies' competitive advantage that should not be ignored (White \& Moraschinelli, 2009). In other words there is not any other entity with such an important effect and influence to reach competitive advantage (Burns, 2008). Trung (2014) believed that a strategic position of managers is necessary to obtain sustainable competitive advantage and improve companies' position among competitors.

\subsubsection{Ensuring of competitive advantage}

In some cases it is impossible for competitors to imitate however it is quite rare. Imitation is one of the most challenging issues for an organization trying to sustain a competitive advantage. Therefore a firm should invest on raising a barrier to imitation in order to ensure sustainability of competitive advantage. Although it is inevitable that a competitive advantage cannot be quite sustainable and finally competitors can find a way to realize how they can imitate the strategy using by the firm (Christensen, 2001). However there is no insuperable barrier to imitation, an organization has to prolong the competitive advantage with emphasis on two proposed strategies as follow. First, organizations should make their effort to prevent competitors comprehend the foundation of their strategy and realize how they create the competitive advantage. Second, strategies have to use an array of activities instead of using a single activity. This means matching an array of interlocked activity and making an ambiguous strategy to implement which is harder for the competitors to duplicate. As this approach reduces the probability of competitors' imitation, it may ensure competitive advantage.

\subsubsection{Sustainable competitive advantage}

It has to be acknowledged that reaching a competitive advantage has been a matter of significance for an organization since before and much attention has been devoted to this issue by a wide range of experts and specialists. The most important subject in a competitive advantage concept is associated 
with the possible signs of a competitive advantage. According to the literature review and experts' views on the subject, the mentioned measures have been classified into three categories including market, finance and customer. A sustained competitive advantage is obtained through unique values which are creating a strategy that any other current or potential competitor is unable to imitate or imply it simultaneously and finally the using strategy cannot be duplicated for long period of time.

\section{Customer}

A core competence which is defined as a skill enabling an organization to create a fundamental value and to lead to customer loyalty should result to customer perceived value. Studies show that customer loyalty and customer attention are two challenging concepts that all organizations encounter. It is exactly clear that loyal customers can raise sales and customer share and reduce costs and higher prices (Alrubaiee \& Alnazer, 2010). As a result, our study seeks to address two critical dimensions of competitive advantage with focus on customers, including flexibility and responsiveness. Flexibility refers to organization capabilities to provide a superior customer value (Johnson et al., 2008) and responsiveness is defined as an organization ability to quickly respond to their customers' requirements (Sousa et al., 2010). A competitive advantage can be obtained through meeting organizational goals and customer needs in a highly competitive environment (Evans et al., 2009). Therefor organizations should fight against each other for capturing customer attention and making a loyal customer. In other words a competitive advantage is reached when customer needs and wants are met more effectively than competitors for a long time by a company, however their competitors make attempt to duplicate, reproduce and even surpass the competitive advantage.

\section{Market}

In 2010 a study conducted by Li and Zhou (2010) to investigate how market orientation and managerial ties can impact competitive advantage. This research showed that one of the most important dimensions of a firm's competitive advantage is institutional advantage which means an organization's superiority in obtaining rare sources and institutional support. In this context it is stated that brands and corporate images have significant impacts on sustained competitive advantage required for a highly competitive environment (Seetharaman et al., 2001; Amini et al., 2012).

\section{Finance}

Reaching a competitive advantage results to a position for a company due to which it can achieve and sustain above average profitability for some years (Jones \& Hill, 2013). It has to be noted that a profit is gained through sales incomes results from customer purchase (Rijamampianina et al., 2003; Thompson et al., 2012).

\section{Research model and hypotheses}

Derived from the existing literature, the proposed relationships among dynamic capability and factors of sustainable competitive advantage in the banking industry are discussed and hypotheses related to these variables are developed. Their search framework generated in this study is illustrated in Fig. 1. This framework briefly proposes that the four different items of DC in the banking industry will enhance its SCA, which will then improve market, customer and financial performances. On the other hands, this paper aims to investigate the underlying influencing mechanism between DC and SCA in the banking industry. It examines what types of components are most crucial to be converted into competitive advantage through DC, describes and understands factors of SCA and also determines relationship between DC and SCA in the banking industry of Iran. So this paper proposes three following hypotheses. 
Hypothesis 1: Dynamic capability (DC) is positively associated with Market based sustainable competitive advantage (MSCA).

Hypothesis 2: Dynamic capability (DC) is positively associated with customer based sustainable competitive advantage (CSCA).

Hypothesis 3: Dynamic capability (DC) is positively associated with financial based sustainable competitive advantage (FSCA).

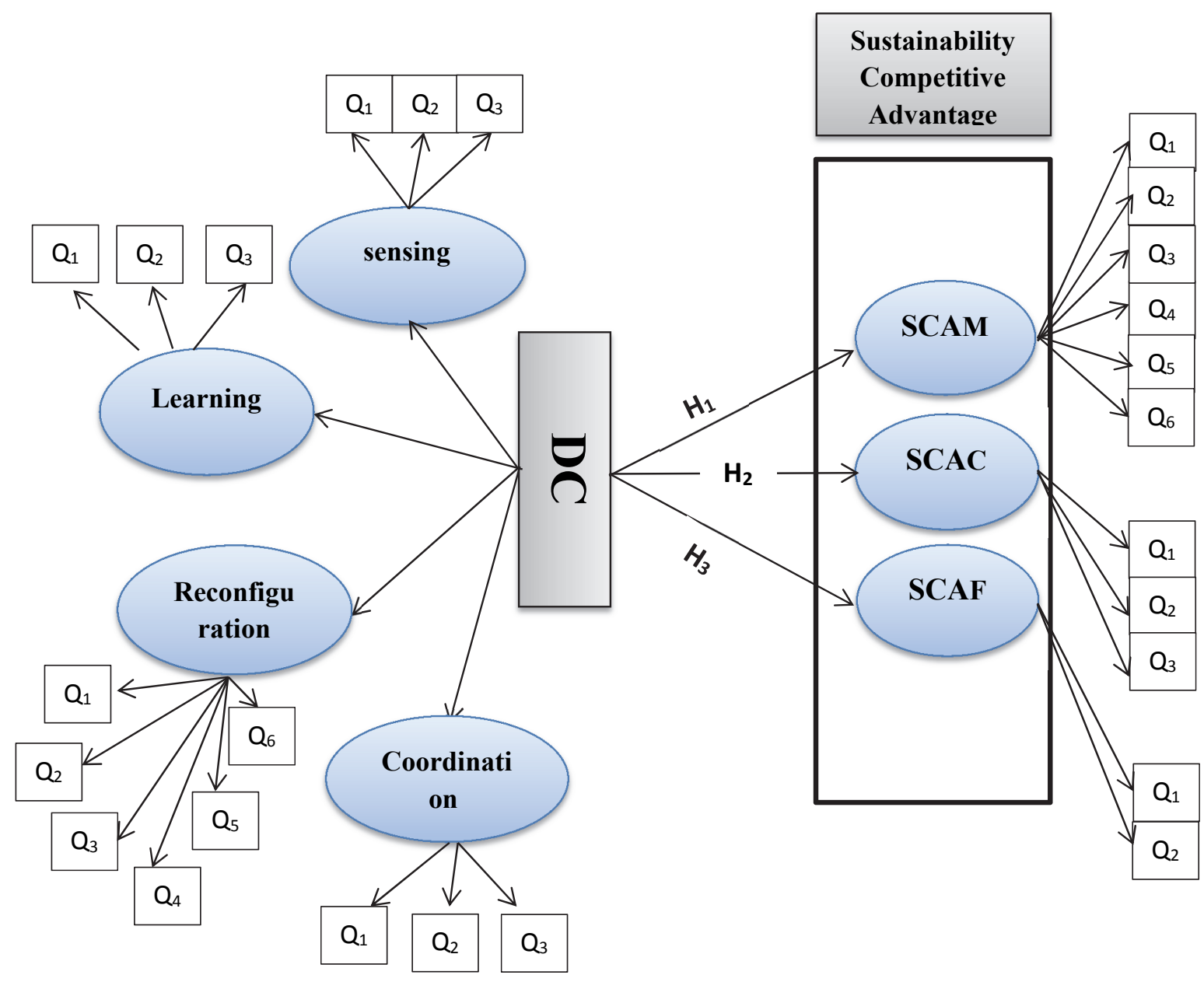

\section{Methodology}

Fig. 1. Conceptual model between DC and SCA

In this section, the sample, procedures of data collection, operational measures of variables and statistical analyses are studied in order to determine the links between dynamic capabilities and sustainable competitive advantage.

\subsection{Sample and procedures}

The banking industry is a major part of Iran's economy. After the study of the performance statistics and information of Iranian banks, the interviews were conducted with expert academics in the banking industry and 50 of the deputy and directors of Iran banks. After all statistical studies and discussions, Mellat Bank was chosen as case study because of the implement of appropriate strategies in maintains and enhance of its competitive advantage among other Iranian banks. The research has been shown MBI has reached to find the competitive advantage among their competitors in recent years. For this reason, this research attempts investigate this practical success in the context of scientific study. 
Following the investigations conducted different strategies lead to achieve these advantages. One of the most important strategies is the dynamic capability and its implementation in the Mellat bank. MBI has the considerable growth in the competition with rival, turned a suitable locale for research to examine the influence of DC on SCA in the banking industry. As an effort to ascertain the content validity of the survey questionnaire, a draft survey was pre-tested by both academicians (i.e. two Strategic Management Assistant Professor) and practitioners (i.e. ten managers' Bank). The participants were requested to evaluate the survey questionnaire on its wording, clarity and relevancy. Ultimately, the final version of questionnaire was distributed randomly to those who are in the executive or Senior Managers, specialists and consultants from the administration and improvement methods, marketing, strategy, risk management and operations manager department of MBI. The reason of choosing this group of professionals as the unit for analysis is because they are the most knowledgeable in terms of the research issues of the study. Out of 150 questionnaires circulated, 122 were returned with complete answers, which represent a response rate of $81.3 \%$. The number of valid and usable questionnaires was 101. The Fig. 2 shows the company characteristics and the target respondents. The Fig. 2 shows that the majority of Respondents, 81.1 percent, are males that are consistent with the Iranian society which is still relatively a male dominated especially on the top management positions. The majority of managers are middle-aged and well educated. This is consistent with the Iranian society that is described as Middle-aged and enjoys high levels of education in the bank department. Being well educated would greatly help MBI in building and accumulating DC to reach SCA now and in the future.

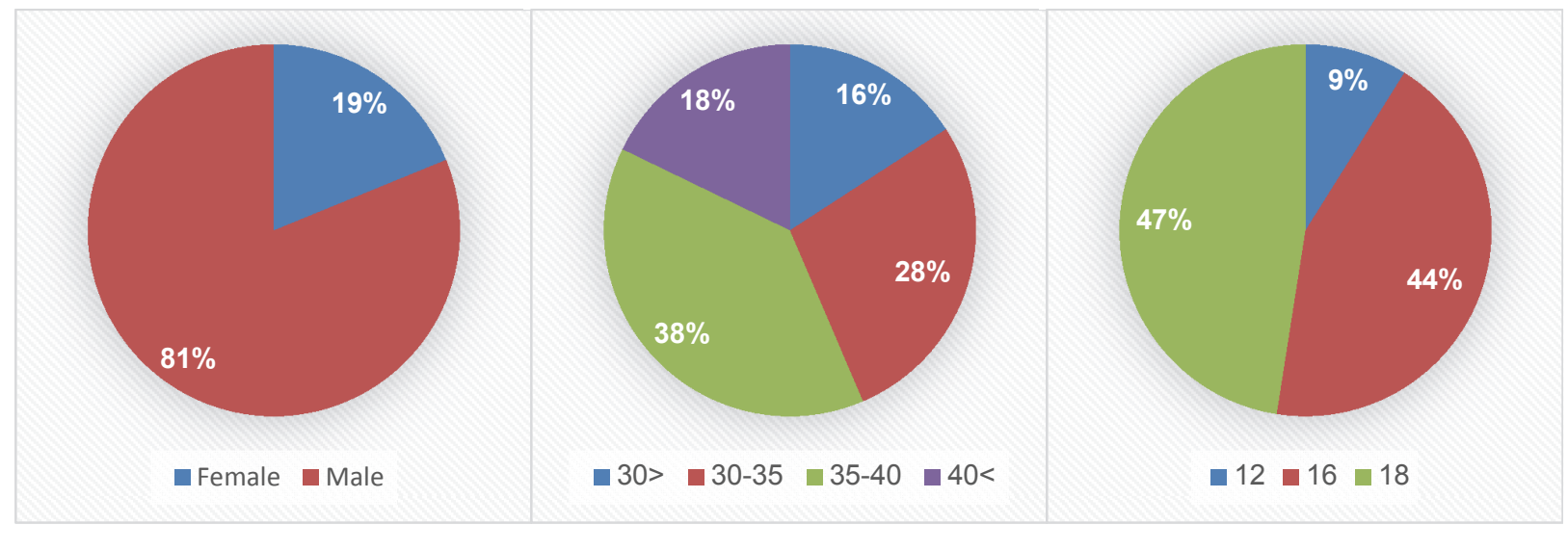

Gender

Age

Years of education

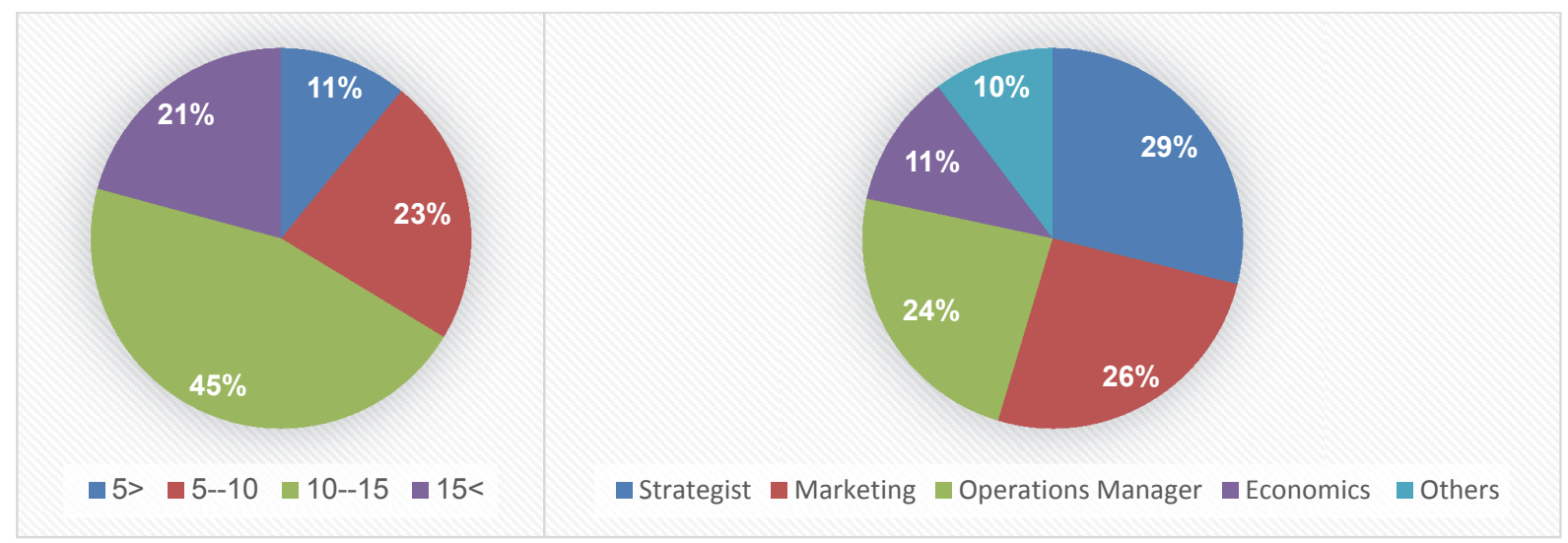

Job experience

Educational background

Fig. 2. Personal characteristics of the participants 
Also, the Fig. 2 shows that the majority of managers, 67 percent, is well experienced in this industry and has more than ten years of experience. This holds a strategic implication that indicates that MBI has relevant and sufficient business industry experience that is crucial for building and sustaining assets and capabilities as a source of competitive advantage for a long time. Finally, the Fig. 2 shows that 61.6 percent of managers have business education background which indicates there is reasonable recruitment process in the bank that focus on quality of people as one of their major assets to achieve a success. The part of measure is organized into two sections that present how to measure the dimension of each construct. It should be mentioned, in order to assess the precision and focuses of the respondents, some questions were designed negatively.

\subsection{Measures of DC}

Four dynamic capabilities dimensions including: sensing, learning, reconfiguration, and coordination focus were evaluated in this study. These dynamic capabilities dimensions were selected based on the studies carried out by Teece (2007) and Menon (2008). Each of these dynamic capabilities practices was measured via a five-item, 5-point Likert scale ranging from strongly disagree $=1$ to strongly agree $=5$.

\subsection{Measures of SCA}

A review of the literature concerning the sustainable competitive advantage in service institutions such as banks found that most research assessed the construct of service institutions from the market, costumer and financial perspective (Johnson et al., 2008). Despite the market, customer and a financialcentre approach for service delivery, very few studies indeed have measured sustainable competitive advantage from these perceptive. The paper focuses on studies investigating the association between areas of sustainable competitive advantage and dynamic capability. The construct measurement is by using a five-item index which includes the three fundamental constructs of SCA (i.e. market, customer, financial). Each of these SCA practices was separately measured and analysis. In order to measure respondents' perception towards the SCA within bank, a 5-point Likert scale was developed $(1=$ strongly disagree; $5=$ strongly agree).

\subsection{Statistical data analysis}

In this study, a Structural Equation Modelling (SEM), Exploratory Factor Analysis (EFA) and Confirmatory Factor Analysis (CFA) were used on the multi-item measure in this study .In order to perform the SEM technique, the data analysis was performed in four steps: first is to examine the KMO and bartlett's test, second, is to perform the exploratory factor analysis, third, is to carry out the confirmatory factor analysis and finally, is examining the hypotheses through SEM.

\subsubsection{KMO and Bartlett's Test of Sphericity (Factor Analysis)}

The Kaiser-Meyer-Olkin (KMO) measure of sampling adequacy tests whether the partial correlations among variables are small. The Kaiser-Meyer-Olkin measure of sampling adequacy is an index for comparing the magnitudes of the observed correlation coefficients to the magnitudes of the partial correlation coefficients. Another indicator of the strength of the relationship among variables is Bartlett's test of sphericity. Bartlett's test of sphericity tests whether the correlation matrix is an identity matrix, which would indicate that the factor model is appropriate. This test is used to test the null hypothesis that the variables in the population correlation matrix are uncorrelated. The KMO measures the sampling adequacy which should be greater than 0.5 for a satisfactory factor analysis to proceed. Looking at the tables 1 and 2, the KMO measure is 0.794 and 0.820 for DC and SCA, respectively. Large values for the KMO measure indicate that a factor analysis of the variables is a good idea. From the same tables, we can see that the Bartlett's test of sphericity is significant. That is, its associated 
probability is less than 0.05 . In fact, it is actually 0.000 . It is small enough to reject the hypothesis. This means that the correlation matrix is not an identity matrix. It is concluded that the relationship among variables is strong. It is a good idea to proceed a factor analysis for the data.

\subsubsection{Exploratory factor analysis}

In order to separate the dimensions of each construct, Exploratory Factor Analysis (EFA) with varimax rotation was performed separately on DC factors and SCA criteria. In the course of the validation process, three items (3 items from SCA factors) were found to have unacceptably low factor loadings of less than 0.5 on their respective unobserved hypothetical or latent variable which were subsequently removed. The internal reliability is evaluated of scales by Cronbach's alpha $(\mathrm{C}-\alpha)$. The result has shown that the Cronbach's alpha value ranges between 0.762 to 0.922 for DC factors, 0.844 for SCA of market entered, $0.777 \mathrm{SCA}$ of customer centered and 0.717 for financial centered indicating the measurement of the variables are well above the acceptable threshold of 0.70 according to Nunnally and Bernstein (1994).

\subsubsection{Confirmatory factor analysis}

A confirmatory factor analysis (CFA) is performed to evaluate the overall measurement model. In order to evaluate the validity of measurement model, convergent and discriminant validity were evaluated. Convergent validity, along with discriminant validity, is a subtype of construction validity. Convergent validity can be estimated using correlation coefficients. Convergent validity refers to the degree to which two measures of constructs that theoretically should be related are in fact related. A successful evaluation of convergent validity shows that a test of a concept is highly correlated with other tests designed to measure theoretically similar concepts.

Table 1

Results of CFA and internal reliability testing \& $\mathrm{K}-\mathrm{M}-\mathrm{O}$ measure

\begin{tabular}{|c|c|c|c|c|c|c|}
\hline Factors & Mean & SD & Loading & AVE & $\mathrm{CR}$ & $\mathrm{C}-\alpha$ \\
\hline Factor 1 & & & & 0.51 & 0.85 & 0.7989 \\
\hline Understanding customer needs and market dynamics & 3.65 & 0.888 & 0.98 & & & \\
\hline Realizing environmental signals and information & 3.58 & 0.941 & 0.79 & & & \\
\hline Reacting quickly and appropriately to all information received from market & 3.61 & 0.927 & 0.91 & & & \\
\hline Factor 2 & & & & 0.56 & 0.76 & 0.765 \\
\hline Releasing information quickly and in time & 3.53 & 0.819 & 0.81 & & & \\
\hline Detecting, verifying, employing, and applying new solutions & 3.46 & 0.954 & 0.80 & & & \\
\hline Generating new ideas and giving them the chance to be real & 3.64 & 0.844 & 0.51 & & & \\
\hline Factor 3 & & & & 0.51 & 0.72 & 0.853 \\
\hline Combining some services into one new service and for using that one again & 2.99 & 1.153 & 0.71 & & & \\
\hline Rotating internal resources such as job rotation for employee & 3.14 & 1.03 & 0.81 & & & \\
\hline $\begin{array}{l}\text { Making appropriate resource configuration in order to respond to environment } \\
\text { changes }\end{array}$ & 3.23 & 1.085 & 0.68 & & & \\
\hline Creating innovation and new solutions in decision making pro & 3.00 & 1.139 & 0.66 & & & \\
\hline $\begin{array}{l}\text { Maintaining wise managers who believe in cooperation and performing such } \\
\text { activities involved cooperation }\end{array}$ & 3.04 & 0.948 & 0.64 & & & \\
\hline Knowledge distribution, allocation, and finally knowledge sharing & 3.27 & 0.944 & 0.87 & & & \\
\hline Factor 4 & & & & 0.59 & 0.79 & 0.805 \\
\hline Putting right people on right places while they are cooperating with each other & 3.53 & 0.963 & 0.79 & & & \\
\hline Cooperating and effectiveness of different sources & 3.44 & 0.806 & 0.64 & & & \\
\hline Giving efficient, flexible and high-quality services & 3.55 & 0.985 & 0.71 & & & \\
\hline
\end{tabular}

$\mathrm{K}-\mathrm{M}-\mathrm{O}$ measure of sampling adequacy $=0.794$; Bartlett test of Sphericity $=957.257 ; \mathrm{p}<0.000$.

A convergent validity has been tested by assessing factor loadings which should be significant and exceed 0.5, composite reliabilities (CR) which should exceed 0.7 , and the average variance extracted (AVE) that should be more than 0.5 for all constructs. In our model, all the factor loadings and composite reliabilities fall in the acceptable ranges and are significant at the 0.001 level. Factor loadings range from 0.52 to 0.98 and 0.52 to 0.94 , Composite reliabilities (CR) range from 0.762 to 0.922 and 0.703 to 0.851 , AVE ranges from 0.522 to 0.860 and 0.556 to 0.659 for DC, SCA, respectively. The results show that our model meets the convergent validity criteria. Table 2 shows the means, SD, factor loading, AVE, CR and C- $\alpha$ of every constructs. Convergent validity can be established if two similar 
constructs correspond with one another, while discriminant validity applies to two dissimilar constructs that are easily differentiated. A successful evaluation of discriminant validity shows that a test of a concept is not highly correlated with other tests designed to measure theoretically different concepts. Fornell and Larcker's approach has been used to assess discriminant validity. In this approach, the AVE for each construct should be higher than the squared correlation between the construct and any of the other constructs. Table 3 indicates that the measurement model has satisfactory discriminant validity. In Table 4, diagonal elements in italics are the AVE and off-diagonal elements are the squared correlations between constructs. It is obvious that each diagonal element is higher than respective offdiagonal elements. Therefore, all constructs in the measurement model were judged as having adequate discriminant validity.

\section{Table 2}

Results of CFA and internal reliability testing \& $\mathrm{K}-\mathrm{M}-\mathrm{O}$ measure

\begin{tabular}{|c|c|c|c|c|c|c|}
\hline Factors & Mean & SD & Loading & AVE & CR & $\mathrm{C}-\alpha$ \\
\hline Factor 1 & & & & 0.522 & 0.874 & 0.844 \\
\hline Integrate performances to find the highest position among all competitors & 3.70 & 0.985 & 0.69 & & & \\
\hline Focusing on market growth and market share indicator & 3.75 & 0.974 & 0.73 & & & \\
\hline Successful in effective in the market & 3.42 & 1.051 & 0.84 & & & \\
\hline $\begin{array}{l}\text { Providing a socially complicated environment which it is difficult for competitors } \\
\text { to imitate }\end{array}$ & 3.58 & 0.930 & 0.71 & & & \\
\hline Fully committing to the society and tries to create value for that & 3.47 & 0.819 & 0.67 & & & \\
\hline \multicolumn{7}{|l|}{$\begin{array}{l}\text { Integration and re-formulation of services and create new services faster than } \\
\text { competitors }\end{array}$} \\
\hline Factor 2 & & & & 0.669 & 0.810 & 0.777 \\
\hline Attractive offers the customers are not superior compared to competitors & 3.27 & 1.067 & 0.66 & & & \\
\hline Providing efficient services with quality and flexibility & 3.32 & 1.104 & 0.92 & & & \\
\hline Investing in customer loyalty and satisfaction and create a positive impression & 3.03 & 1.118 & 0.85 & & & \\
\hline Factor 3 & & & & 0.639 & 0.811 & 0.717 \\
\hline Profit rate is higher than the industry average & 3.30 & 0.922 & 0.58 & & & \\
\hline Increasing the efficiency in the financial processes and save costs & 3.60 & 0.991 & 0.97 & & & \\
\hline
\end{tabular}

Table 3

Discriminant validity analysis

\begin{tabular}{lcccc}
\hline Factors & SEN & LEA & EAC & COR \\
\hline SEN & 0.860 & & & \\
LEA & 0.336 & 0.523 & & \\
REC & 0.116 & 0.160 & 0.510 & 0.662 \\
COR & 0.325 & 0.449 & 0.160 & \\
\hline
\end{tabular}

Table 4

Discriminant validity analysis

\begin{tabular}{lccc}
\hline Factors & SCAM & SCAC & SCAF \\
\hline SCAM & 0.522 & & \\
SCAC & 0.176 & 0.669 & 0.636 \\
SCAF & 0.250 & 0.231 & \\
\hline
\end{tabular}

\subsubsection{The structural model}

Fig. 1 exemplifies the proposed structural model showing the association between the five and three dimensions of DC and SCA, respectively. To examine the model, conventional maximum likelihood estimation approaches were used (Martínez-Costa \& Jiménez-Jiménez, 2009). It is assessed the measurement model fit by evaluating: (1) absolute fit indices including observed normed $\chi^{2}\left(\chi^{2} / \mathrm{df}\right)$, goodness of fit index (GFI), adjusted goodness-of-fit index (AGFI) and adjusted goodness-of-fit index (AGFI); (2) Comparative fit indices including normed fit index (NFI), and comparative fit index (CFI); and (3) parsimonious fit indices including parsimony goodness-of-fit index (PGFI) and parsimony normed fit index (PNFI) and the root mean square error of approximation (RMSEA). The summary results of the structural equation modelling technique are shown in Table 5. Examples of the fundamental measures are the ratio of $\chi^{2}$ statistics to the degree of freedom (df), normed fit index (NFI), 
comparative fit index (CFI), goodness-of-fit index (GFI) and the root mean square error of approximation (RMSEA). Table 5 summarized the results of CFA models, all the model-fit indices are well above their common acceptable levels in which $\chi^{2} / \mathrm{df}$ was less than 3.0 and greater than 0.90 for GFI, AGFI, CFI and NFI as suggested by Bagozzi and Yi (1988), with RMSEA less than 0.08 according to Browne and Cudeck (1993), suggesting that the CFA models fit well. In their studies, Anderson and Gerbing (1988) suggest that values greater than 0.90 are desired for GFI, CFI, AGFI, and NFI while Browne and Cudeck (1993) required values less than 0.08 for RMSEA. Based on Table 5, the ratio of $\chi^{2}$ statistics to the degree of freedom for our model was 2.71 . The value of the remaining fit indices include the GFI $=0.97$; $\mathrm{AGFI}=0.93$; $\mathrm{CFI}=0.91$; $\mathrm{NFI}=0.98$; and RMSEA $=0.061$ ). All the model-fit indices are well above their common acceptable levels, suggesting that the structural model fits well. It can be concluded that a goodness-of-fit exists for the measurement scale of market orientation. It is shown in Fig.3. Therefore, we can conclude that the model fits the data well and thus is able to explain the research hypotheses.

\section{Table 5}

Overall fit indices of the CFA model

\begin{tabular}{lcc}
\hline $\begin{array}{l}\text { Fit index } \\
\text { Absolute fit Indices }\end{array}$ & Scores & Recommended cut-off value \\
\hline$X^{2} /$ df & 2.71 & $\leq 3$ \\
GFI & 0.97 & $\geq 0.9 ; \geq 0.8$ \\
AGFI & 0.93 & $\geq 0.9 ; \geq 0.8$ \\
\hline Comparative fit Indices & & $\geq 0.9$ \\
NFI & 0.97 & $\geq 0.9$ \\
CFI & 0.91 & $\leq 0.08 ; \leq 0.1$ \\
Parsimonious fit Indices & & The higher, the better \\
RMSEA & 0.06 & The higher, the better \\
PGFI & 0.85 &
\end{tabular}

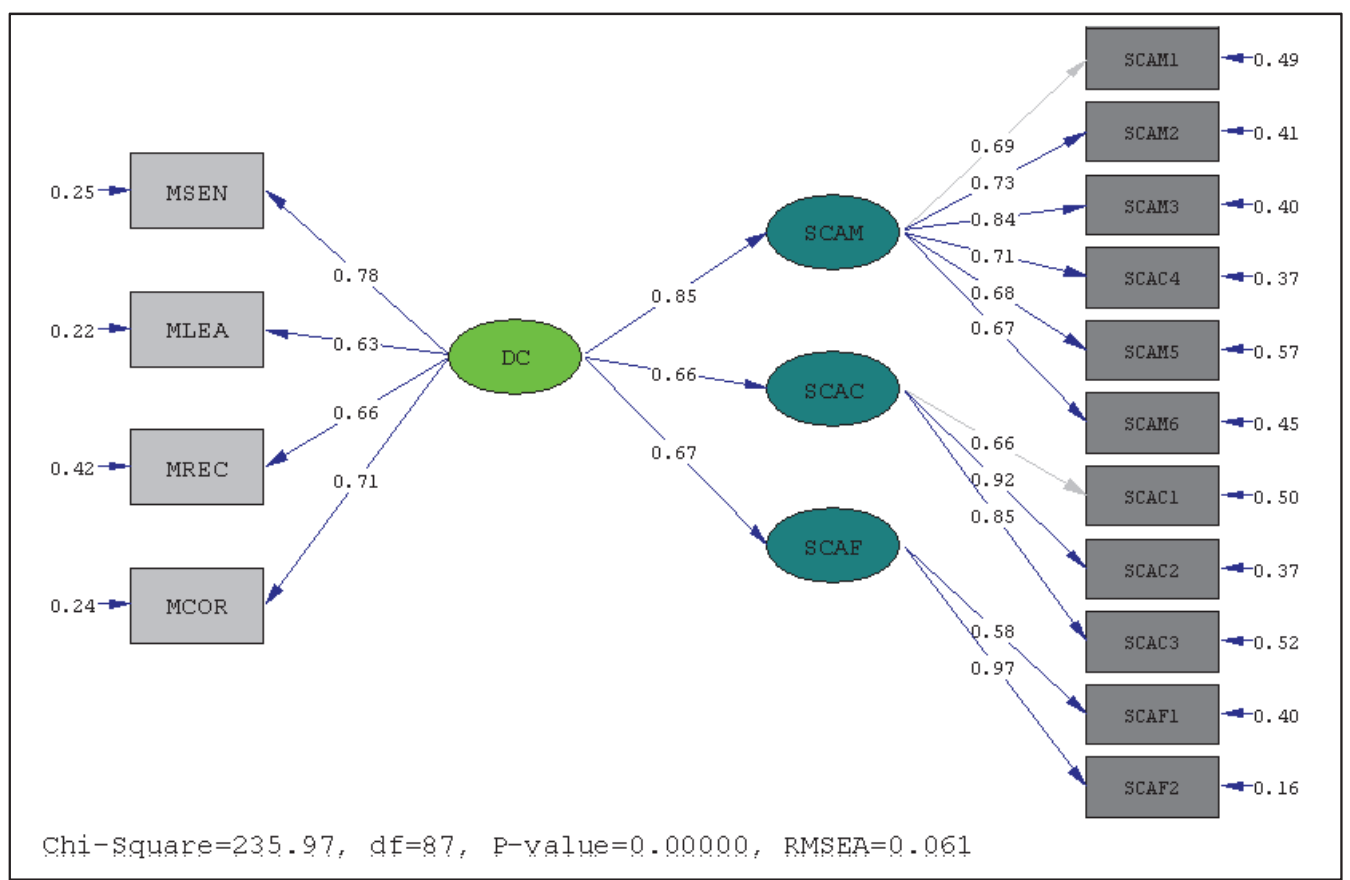

Fig.3. Structural Relationship model between DC and SCA 


\subsection{Hypothesis testing}

The findings (Table 6) for H1 (DC to SCAM, estimate: $0.85 ; \mathrm{p}<0.000$ ) implies that DC has a positive and significant relationship with SCAM in Mellat bank. By adopting the suggested dynamic capability practices, firms will be better able to improve on the level of SCA through a more systematic approach. This result is consistent with the findings of Lin and $\mathrm{Wu}$ (2014), in which the authors found that DC has an effect on the performance, resulting in improved SCA. Pertaining to H2 (DC to SCAC; estimate: $0.66 ; p<0.000)$, the findings revealed that there is a positive relationship between the dimensions of DC and SCAC. This result is supported by the findings of Terziovski (2010) where he found that the intensity of customer management practices showed a positive association with SCAC outcomes. For the third hypothesis, $\mathrm{H} 3$ (DC to SCAF, estimate: $0.67 ; \mathrm{p}<0.000$ ), the results were significant, implying that there is a significant relationship between DC and SCAF.

Table 6

Standardized path coefficients

\begin{tabular}{lccl}
\hline Hypotheses & Estimate & $\mathrm{p}$ & Remarks \\
\hline $\mathrm{H}_{1}$ & 0.85 & $<0.000$ & Supported \\
$\mathrm{H}_{2}$ & 0.66 & $<0.000$ & Supported \\
$\mathrm{H}_{3}$ & 0.67 & $<0.000$ & Supported \\
\hline
\end{tabular}

\section{Discussion}

This paper serves as empirical evidence contributing to the attributes of DC that can be seen on SCA in three areas including the market, costumer and financial. From the analysis, it was shown that DC contributes significantly and positively to SCA. In other words, DC implementation can improve the SCA of the Mellat bank. Our findings are consistent with the studies performed by Lin and Wu (2014) and Jafari and Rezaee (2014). That study supported the strong positive linkage between DC and SCA since dynamic capabilities can mediate the firm's VRIN resources to improve performance and reach sustainable competitive advantage. Furthermore, Stephen (2010) findings about DC principles which serve as an apparatus for a company to achieve SCA have also been supported by our study. The practices of DC used in our study, are somewhat similar to those used by Tees (1997) and Menoon (2008). Thus, once DC practices are in place, market needs can be identified easily and marketing strategy can be further improved, creating values for the customers and accordingly, increase company profits. In other words, market-centered banks have the ability to understand their market targets better. They are more committed to provide premium service quality to their customers. And also, their efforts can lead to the provision of high quality service, which will then result in enhanced company performance. Generally, market-centered service firms are better able to meet the needs and expectations of their customers by providing superior service quality. In summary, when DC dimensions are present in the bank, Banks will be prompt, proper and reliable, thus enhancing the assurance of the bank's services towards the customers. Consequently, increase their profits and productivity.

\section{References}

Alrubaiee, L., \& Al-Nazer, N. (2010). Investigate the impact of relationship marketing orientation on customer loyalty: The customer's perspective.International Journal of Marketing Studies, 2(1), p155.

Anderson, J. C., \& Gerbing, D. W. (1988). Structural equation modeling in practice: A review and recommended two-step approach. Psychological bulletin, 103(3), 411. 
Amini, A., Darani, M., Afshani, M., \& Amini, Z. (2012). Effectiveness of marketing strategies and corporate image on brand equity as a sustainable competitive advantage. Interdisciplinary Journal of Contemporary Research in Business, 4(2), 192-205.

Amit, R., \& Schoemaker, P. (1993), Strategic assets and organizational rent. Strategic Management Journal, 14, 33-46.

Bagozzi, R. P., \& Yi, Y. (1988). On the evaluation of structural equation models. Journal of the academy of marketing science, 16(1), 74-94.

Barney, J.B. (2000). Firm resources and competitive advantage. Advances in Strategic Management, $17,203-227$.

Browne, M. W., \& Cudeck, R. (1993). Alternative ways of assessing model fit. Sage Focus Editions, 154, 136-136.

Burns, P. (2008). Corporate Entrepreneurship: Building the Entrepreneurial Organization, Palgrave Macmillan: New York.

Casson, M. (1997). Information and Organization: A New Perspective on the Theory of the Enterprise. Oxford University Press, New York, NY.

Sousa, C. M., Ruzo, E., \& Losada, F. (2010). The key role of managers' values in exporting: influence on customer responsiveness and export performance. Journal of International Marketing, 18(2), 119.

Christensen. C. M. (2001). The past and future of competitive advantage. MIT Sloan Management Review, 42, 105-19.

Clark, K., \& Fujimoto, T. (1999). Product Development performance: Strategy, organizational and management in the world Auto Industries. Havard Business School Press, Cambridge MA.

Easterby-Smith, M., Lyles, M. A., \& Peteraf, M. A. (2009). Dynamic capabilities: current debates and future directions. British Journal of Management, 20(s1), S1-S8.

Eisenhardt, K. M., \& Martin, J. A. (2000). Dynamic capabilities: what are they?. Strategic management journal, 21(10-11), 1105-1121.

Evans, M., Jamal, A., \& Foxall, G. (2009). Consumer Behavior. West Sussex, England: John Wiley \& Sons Ltd.

Foerstl, K., Reuter, C., Hartmann, E., \& Blome, C. (2010). Managing supplier sustainability risks in a dynamically changing environment-Sustainable supplier management in the chemical industry. Journal of Purchasing and Supply Management, 16(2), 118-130.

Fornell, C., \& Larcker, D. F. (1981). Evaluating structural equation models with unobservable variables and measurement error. Journal of marketing research, 18, 39-50.

Gupta, S., Woodside, A., Dubelaar, C., \& Bradmore, D. (2009). Diffusing knowledge-based core competencies for leveraging innovation strategies: Modelling outsourcing to knowledge process organizations (KPOs) in pharmaceutical networks. Industrial Marketing Management, 38(2), 219227.

Hamel, G., \& Prahalad, C. K. (1990). Corporate imagination and expeditionary marketing. Harvard business review, 69(4), 81-92.

Hamidizadeh, M. R., \& Taheri, M. (2013). A comprehensive literature review in competitive advantages of businesses. Asian Journal of Research in Marketing, 2(6), 76-97.

Helfat, C. E., \& Peteraf, M. A. (2003). The dynamic resource-based view: capability lifecycles. Strategic management journal, 24(10), 997-1010.

Helfat, C., \& Peteraf, M. (2009). Understanding dynamic capabilities: progress along a developmental path. Strategic organization, 7(1), 91.

Helfat, C. E., \& Raubitschek, R. S. (2000). Product sequencing: co-evaluation of knowledge, capabilities and products. Strategic Management Journal, 21, 961-79.

Helfat, C. E., Finkelstein, S., Mitchell, W., Peteraf, M., Singh, H., Teece, D., \& Winter, S. (2007). Dynamic capabilities: understanding strategic change in organizations. Blackwell Publications, Malden.

Holliday, C. (2001). Sustainable growth, the DuPont way. Harvard business review, 79(8), 129-34. 
Iansiti, M., \& Clark, K. B. (1994). Integration and dynamic capability: evidence from product development in automobiles and mainframe computers. Industrial and corporate change, 3(3), 557605.

Jafari, M., \& Rezaee, F. (2014). The effect of resource based view on sustainable capability advantage. Management Science Letters, 4(12), 2537-2554.

Johnson, G., Scholes, K., \& Whittington, R. (2008). Exploring corporate strategy; Text and Cases. FT Prentice Hall, Pearson Education.

Jones, G.R., \& Hill, C.W.L. (2013). Theory of strategic management with cases. Canada: SouthWestern, Cengage Learning.

Li, J. J., \& Zhou, K. Z. (2010). How foreign firms achieve competitive advantage in the Chinese emerging economy: Managerial ties and market orientation. Journal of Business Research, 63(8), 856-862.

Lin, Y., \& Wu, L. Y. (2014). Exploring the role of dynamic capabilities in firm performance under the resource-based view framework. Journal of Business Research, 67(3), 407-413.

Ljungquist, U. (2008). Specification of core competence and associated components: A proposed model and a case illustration. European Business Review, 20(1), 73-90.

Makkonen, H., Pohjola, M., Olkkonen, R., \& Koponen, A. (2014). Dynamic capabilities and firm performance in a financial crisis. Journal of Business Research, 67(1), 2707-2719.

Martínez-Costa, M., \& Jiménez-Jiménez, D. (2009). The effectiveness of TQM the key role of organizational learning in small businesses.International Small Business Journal, 27(1), 98-125.

Mathiassen, L., \& Vainio, A. M. (2007). Dynamic capabilities in small software firms: A sense-andrespond approach. Engineering Management, IEEE Transactions on, 54(3), 522-538.

Terziovski, M. (2010). Innovation practice and its performance implications in small and medium enterprises (SMEs) in the manufacturing sector: a resource-based view. Strategic Management Journal, 31(8), 892-902.

Menon, A. G. (2008). Revisiting dynamic capability. IIMB Management Review, 20(1), 22-33.

Menon, A. G., \& Mohanty, B. (2008, December). Towards a theory of" dynamic capability" for firms. In 6th AIMS International Conference on Management (pp. 28-31).

Nonaka, I., \& Toyama, R. (2007). Strategic management as distributed practical wisdom (phronesis). Industrial and Corporate Change, 16(3), 371-394.

Nonaka, I., Toyama, R., \& Norboru, K. (2001). A unified model of dynamic knowledge creation. Long Range Planning, 33, 5-34.

Nunnally, J.C., \& Bernstein, I.H. (1994). Psychometric Theory. McGraw-Hill, New York, NY.

Oliver, R.L. (2000). Whence consumer loyalty? Journal of Marketing, Special Issue, 63, 33-44.

Pavlou, P. A., \& Sawy O. A. (2006), Decomposing and leveraging dynamic capabilities. School of Management, University of California.

Pearce, J. A., \& Robinson. R. B. (2000). Strategic management: formulation, Implementation, and Control. Irwin Mc Graw- Hill, Boston, MA.

Porter. M. E. (1987). From competitive advantage to corporate strategy. Harvard Business Review, 65, 43-59.

Porter., M. E. (1996). What is strategy?. Harvard Business Review, 74, 61-78.

Prahalad., C. K., \& Hamel., G. (1990). The core competence of the corporation. Harvard Business Review, 68, 79-91.

Reed, R., \& Defillippi, R. (1990). Casual ambiguity, barriers to imitation, and sustainable competitive advantage. Academy of Management Review, 15, 88-102.

Rezaee, F., \& Jafari, M. (2015). The effect of marketing knowledge management on sustainable competitive advantage: Evidence from banking industry. Accounting, 1(2), 69-88.

Rijamampianina, R., Abratt, R., \& February, Y. (2003). A framework for concentric diversification through sustainable competitive advantage. Management Decision, 41(4), 362-371.

Seetharaman, A., Nadzir, Z.A.B.M., \& Gunalan, S. (2001). A conceptual study on brand valuation. Journal of Product and Brand Management, 10(4), 243-256. 
Stephen, N. (2010). Dynamic capabilities, organizational citizenship behavior and managed performance in business. Technical and Vocational Education Training Institutions, working paper [HD10/11135U], Human resource Management, Makerere University, July.

Teece, D. J. (2007). Explicating dynamic capabilities: the nature and micro foundations of (sustainable) enterprise performance. Strategy Management Journal, 28, 1319-50.

Teece, D. J., Pisano, G., \& Shuen, A. (1997). Dynamic capabilities and strategic management. Strategic Management Journal, 18, 509-33.

Thompson, A., \& Peteraf, M.A., Gamble, J.E., \& Strickland, A.J. (2012). Crafting and executing strategy concepts and readings. McGraw Hill Irwin: New York.

Trung, T.D.H. (2014). Obtaining sustainable competitive advantage from customer loyalty: A perspective of marketing-mix strategy and corporate social responsibility. Working paper, Department of international business administration, College of Business Chinese Culture University.

Van Den Bosch, F. A., Volberda, H. W., \& De Boer, M. (1999). Coevolution of firm absorptive capacity and knowledge environment: Organizational forms and combinative capabilities. Organization science, 10(5), 551-568.

Winter, S. G. (2003). Understanding dynamic capabilities. Strategic management journal, 24(10), 991995.

Wang, C. L., \& Ahmed, P. K. (2007). Dynamic capabilities: A review and research agenda. International journal of management reviews, 9(1), 31-51.

White, B.A., \& Moraschinelli, E. (2009). The pursuit of sustainable competitive advantage - A profile of the starbucks corporation. Working paper, International Business and Entrepreneurship, Malardalen University.

Zahra, S.A., \& George, G. (2002). Absorptive capacity: a review, reconceptualization, and extension. Academy of Management Review, 27, 185-203.

Zahra, S. A., Sapienza, H. J., \& Davidsson, P. (2006). Entrepreneurship and dynamic capabilities: a review, model and research agenda. Journal of Management studies, 43(4), 917-955.

Zollo, M., \& Winter, S. G. (2002). Deliberate learning and the evolution of dynamic capabilities. Organization Science, 13, 39-51.

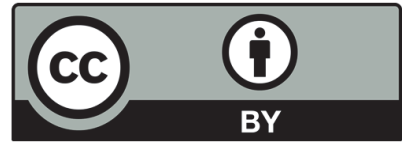

(C) 2016 by the authors; licensee Growing Science, Canada. This is an open access article distributed under the terms and conditions of the Creative Commons Attribution (CC-BY) license (http://creativecommons.org/licenses/by/4.0/). 